\title{
O GRÁBEN DE CANANÉIA
}

\section{LUIZ ANTONIO PEREIRA DE SOUZA*; MOYSÉS GONSALEZ TESSLER** \& VICENTE LUIZ GALLI*}

\begin{abstract}
THE Cananéia graben This paper aims to contribuite for the best understanding of the geological evolution of Cananéia-Iguape coastal plain by using Gravity method. Gravity survey was performed on Cananéia-Iguape region in the southern part of the State of São Paulo, Brazil. The survey was conducted on 280 gravity stations along this area, which has never been surveyed before by using this method. Analysis of achieved data allowed the identification of two significant gravity anomalies: one refers to a prominent gravity high related to the basement rock reached at a deph of 47 meter (well IGG-1) ; the other one, refers to a large gravity low and corresponds to a thick sediment basin located in the central portion of Cananéia Island and southern part of Comprida Island. Two topographic profiles of the basement rock in the surveyed area were achieved by analysing the gravity data along two longitudinal modelled cross-sections of Comprida Island. It shows a thickening of the sedimentary deposit towards the continent in the area of gravity low. The interpretation of gravity data in conjunction with geological and aeromagnetic data shows that the evolution of this coastal plain may be conditioned by a system of normal faults, which may define the graben here named Cananeia Graben.
\end{abstract}

Keywords: Cananeia, Cananeia Graben, Iguape, coastal geology, gravity

Resumo Este trabalho visa contribuir para o estudo da evolução geológica da planície costeira Cananéia-Iguape, litoral sul do Estado de São Paulo, tendo como base dados geofísicos obtidos através do método de Gravimetria. Foram estabelecidas 280 estações de gravimetria abrangendo um setor da costa do Estado de São Paulo, até então não coberto por levantamentos desta natureza. A análise dos dados propiciou a identificação de um alto gravimétrico coincidindo aproximadamente com o local da sondagem IGG-1, que atinge o embasamento à profundidade de $47 \mathrm{~m}$. Permitiu também a identificação de um baixo gravimétrico na área correspondente à porção central da ilha de Cananéia e sul da ilha Comprida. O modelamento dos dados gravimétricos, ao longo de dois perfis longitudinais às ilhas Comprida e Cananéia, permite definir a conformação topográfica aproximada do embasamento cristalino nestas ilhas, bem como indica um espessamento da cobertura sedimentar no rumo do continente na área do baixo gravimétrico. Esta interpretação permite supor a existência, neste setor da área investigada, de um sistema de falhas, provavelmente normais, com basculamento de blocos para NW, relacionadas com reativações cenozóicas, 0 que configura a existência de um graben ou semigráben denominado neste trabalho de Graben de Cananéia.

Palavras-chaves: Cananéia, Graben de Cananéia, Iguape, geologia costeira, gravimetria

Introdução Apesar de se considerarem as margens do tipo Atlântico, em princípio, sismicamente inativas, alguns autores brasileiros têm encontrado evidências localizadas de atividade tectônica cenozóica ao longo da costa brasileira.

Almeida (1976) admite que processos tectônicos cenozóicos no Estado de São Paulo estejam relacionados com a elevação epirogenética generalizada ocorrida no Plioceno.

As varias reativações sofridas pela margem continental brasileira, após a separação da Africa e América, foram traduzidas no continente por diversos eventos, como por exemplo, o levantamento da Serra do Mar, a formação das fossas tectônicas do Paraíba do Sul e da Guanabara e a própria subsidência da bacia de Santos (Almeida 1976).

Considerando-se que provavelmente estes mecanismos tenham sido atuantes até o Quaternário, parece viável admitir que, durante o Cenozóico, tenha existido uma linha de inflexão na região intermediária entre o continente e o mar, produto do balanceamento entre uma zona positiva sobre o continente e uma negativa no mar.

Martin et al(1984), para o litoral do Estado da Bahia, encontraram evidências de tectonismo quaternário a partir da análise da morfologia atual e do desnivelamento, no espaço, de antigas linhas de costa quaternárias.

Para o litoral paulista, Petri \& Fúlfaro (1970) analisando a geologia e os terraços marinhos da ilha do Cardoso, litoral sul, observaram que alguns terraços marinhos de abrasão e depósitos de tálus litificados e cortados dão a idéia de uma emergência daquela porção da costa sul do Estado.

Todavia, Suguio \& Petri (1973), analisando os resultados de levantamentos geofísicos (métodos geoelétricos, resistivi- dade e gravimétricos) executados em trechos restritos da ilha Comprida, próximo à ilha do Cardoso, descreveram a existência de um desnivelamento entre o embasamento da ilha Comprida, mais profundo, e o do continente próximo localizado a menores profundidades. Este fato, que poderia significar a existência de falhas, em um segmento de costa contíguo ao Cardoso, foi explicado pelos autores como reflexo do simples mergulho natural $(1 / 100)$ do embasamento da região, rumo ao oceano.

Martin \& Suguio (1975), na tentativa de explicar o comportamento diferente da costa sudeste, com aparente características de emersão, em relação à costa nordeste, com aparente características de submersão, admitiram , para a costa paulista, fracos movimentos tectônicos durante o Holoceno e movimentos mais intensos durante o Pleistoceno.

Mioto (1983), estudando as zonas sismogênicas do sudeste do Brasil, apresenta evidências de que uma acomodação relacionada com a epirogênese vem sendo observada nessa região. Na área limítrofe dos Estados do Paraná e São Paulo, Mioto (1993) demonstra existir uma íntima relação entre a sismicidade e a tectônica contemporânea, atribuindo a este fato a manutenção do equilíbrio isostático entre as porções continentais emersa (Serra do Mar) e submersa (bacia de Santos).

O estudo da compartimentação estrutural e da evolução tectônica do Estado de São Paulo estabelece, com base numa série de dados sismológicos preexistentes, sete zonas sismogênicas no Estado de São Paulo, com a sugestão da existência da zona sismogênica de Cananéia (IPT 1989), onde foram caracterizados vários lineamentos estruturais, em especial, o 
de Guapiara, NW-SE (Ferreira et al. 1981) e a extensa sutura NE/SW, na altura da região de Eldorado, no sul do Estado.

Outros autores têm feito referência à existência de um condicionamento tectônico na formação da costa sudeste do Estado de São Paulo, em particular Fúlfaro et al. (1974), Teissedre et al(1981), Riccomini (1987), Miranda (1970) e Pressinoti \& Pressinotti 1980.

Assim, um dos objetivos do presente trabalho é contribuir para a compreensão da evolucão geológica da planície costeira Cananéia-Iguape, litoral sul do Estado de São Paulo, a partir de dados geofisicos, permitindo delinear o arcabouço estrutural e tectônico sobre o qual se desenvolveu esta planície costeira.

Localização da área de estudo $\mathrm{A}$ área estudada abrange a faixa costeira sul do Estado de São Paulo, pertencente à planície costeira Cananéia-Iguape. Localiza-se, aproximadamente, entre os paralelos $24^{\circ} 37^{\prime}$ e $25^{\circ} 07^{\prime} \mathrm{S}$ e os meridianos $47^{\circ} 23^{\prime}$ e $48^{\circ} 05^{\prime} \mathrm{W}$, limitando-se ao sul com o Estado do Paraná e ao norte com a foz do rio Ribeira de Iguape. Compreende basicamente as ilhas de Cananéia, do Cardoso, de Iguape e Comprida, além da faixa continental adjacente, ocupando parte dos municípios de Cananéia, Iguape, Ilha Comprida e Pariqüera-Açu. As principais cidades na área de estudo são Cananéia e Iguape (Fig. 1).

\section{Geologia da Planície Costeira Cananéia-Iguape}

$\mathrm{O}$ embasamento cristalino ao redor da Planície Costeira $\mathrm{Ca}-$ nanéia-Iguape é de idade Pré-cambriana e de origem metamórfica, vinculado ao Grupo Açungui (Relatório Projeto Sudelpa 1975, apud Tessler 1982). Compõe-se basicamente de rochas metamorficas tais como filitos, micaxistos e gnaisses. Ocorrem também outros tipos de rochas, como quartzitos, anfibo- litos, diabásios e calcioxistos, ao longo do rio Ribeira de Iguape, intrudidos por granitos, adamelitos e granodioritos.

Cortando todo esse complexo, afloram rochas alcalinas intrusivas mesozóicas, tendo como exemplos o morro de São João, no município de Cananéia, e o Morrete, no município de Ilha Comprida.

Estratigrafia A Planície Costeira Cananéia-Iguape é, em grande parte, coberta por depósitos arenosos marinhos extremamente homogêneos, compostos de areias finas muito bem-selecionadas.

A bacia de drenagem da área compõe-se de rios de alto gradiente, no trecho a montante, porém bastante suave na sua foz, junto à planície. A influência marinha é comum na maioria dos rios, e se estende muitas vezes por vários quilômetros a montante da foz.

O complexo relacionamento entre esses rios e as oscilações de maré, influenciando a salinidade e os processos hidrodinâmicos na região, propicia o desenvolvimento de vários subambientes de sedimentação atuais.

A estratigrafia das sequências sedimentares cenozóicas desta planície costeira foi estabelecida por Petri \& Suguio (1971, 1973) e Suguio \& Petri (1973), com base em observaç̃es de campo e nos resultados de sondagens mecânicas executadas na área pelo antigo Instituto Geográfico e Geológico - IGG (IGC1989) e pela Geobrás S .A. - Engenharia e Fundações (GEOBRÁS 1966), além dos resultados dos ensaios geofísicos referidos em Petri \& Suguio (1971), executados no início da década de 60.

Estes autores, fundamentados nas interpretações das análises granulométricas, mineralógicas e do conteúdo de foraminíferos e diatomáceas realizadas nos testemunhos das sondagens IGG-1 e IGG-2, associadas à análise de dados

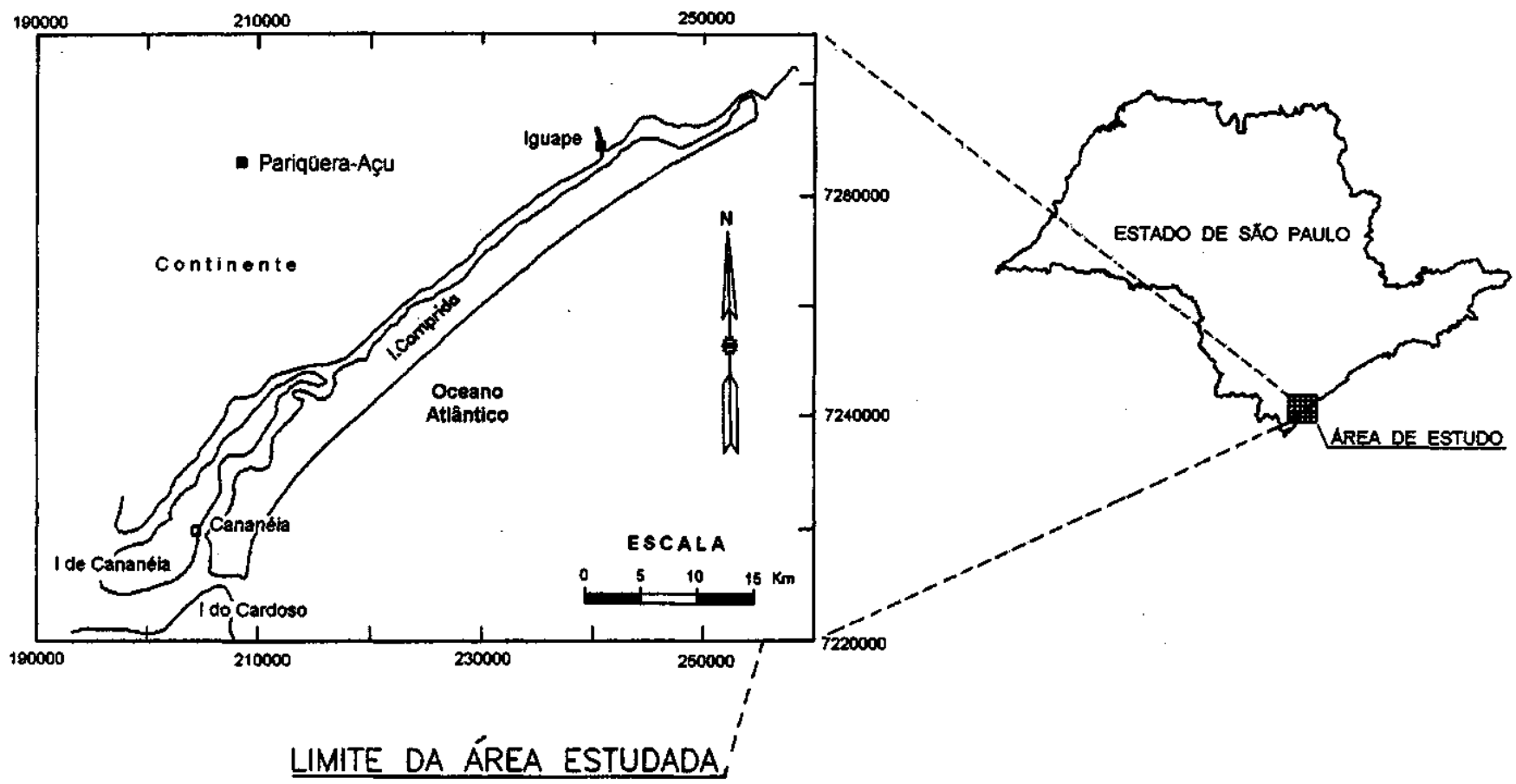

Figura 1 - Mapa de localização da área estudada Figure l - Location of studied area 
geofísicos, subdividiram o. pacote sedimentar em quatro sequências, que variam de sedimentos continentais na base para sedimentos francamente marinhos no topo, constituindo uma coluna sedimentar de espessura variável, que em alguns pontos atinge pelo menos $167 \mathrm{~m}$.

Gênese A gênese da planície costeira Cananéia-Iguape tem sido discutida por vários autores. Besnard (1950 apud Tessler 1982) baseou-se nas características geomorfológicas da região lagunar, para concluir sobre sua gênese. Para este autor a atual região de Cananéia-Iguape teria sido um golfo vinculado ao processo de recuo da Serra do Mar para o interior. Suguio \& Martin (1978a,b) elaboraram um modelo de evolução com base na coluna estratigráfica local e suas relações espaciais e temporais. Estes autores apresentaram um mecanismo de formação da planície quaternária CananéiaIguape através de um modelo evolutivo subdividido em cinco estádios a partir da transgressão Cananéia (120.000 anos), atingindo seu último estágio evolutivo quando, no Holoceno, o mar atinge seu nível atual, e originam-se os cordões arenosos litorâneos de regressão de diferentes fases, devido às oscilações do nível do mar nessa época.
Aquisição e Tratamento dos Dados Gravimétricos A aplicação do método de gravimetria, no estudo desta planície costeira (Souza 1995), baseou-se na perspectiva da existência de contrastes de densidade expressivos entre as camadas de sedimentos (continentais, na base e marinhos no topo), que constituem a coluna estratigráfica da área e o embasamento cristalino. De maneira geral, o preenchimento por sedimentos de uma depressão aberta na crosta terrestre causa anomalia negativa, refletindo deficiência local de massa. Em alguns casos, entretanto, o processo de rifteamento crustal pode ser acompanhado de eventos de injeção de material magmático, que darão origem a corpos intrusivos de densidade mais alta em relação ao meio, que por sua vez poderão produzir anomalias positivas.

Foram instaladas ao longo da faixa litorânea da planície costeira Cananéia-Iguape um total de 280 estações gravimétricas, distanciadas entre si de aproximadamente $1 \mathrm{~km}$. Os gravímetros utilizados foram da marca Lacoste \& Romberg (Geodetic Gravity Meter) modelo G, pertencente ao Instituto Astronômico e Geofísico - IAG/USP.

A maioria das medições foi realizada, simultaneamente, por dois gravímetros. Este procedimento garantiu maior pre-

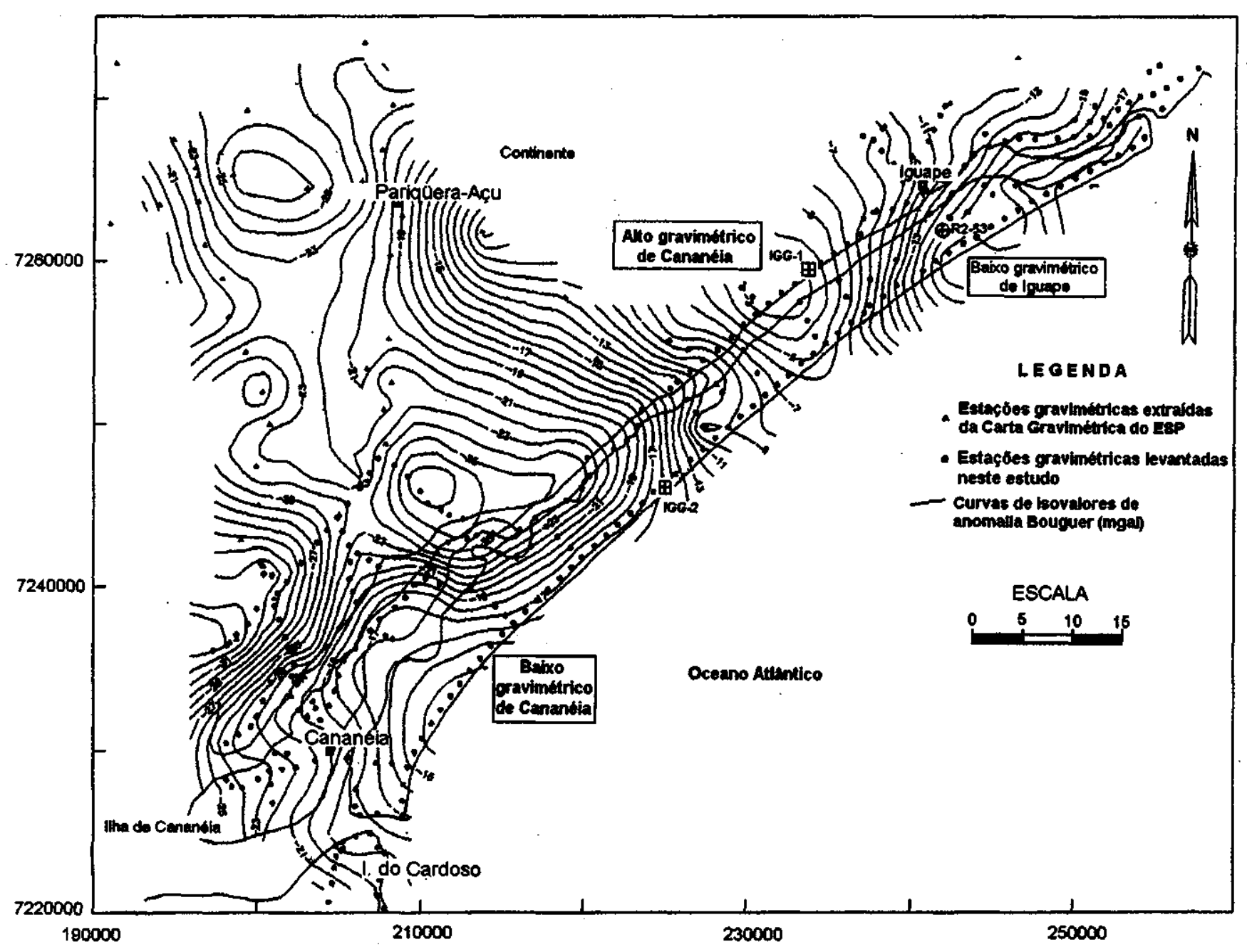

Figura 2 - Mapa Bouguer da área estudada (Souza 1995)

Figure 2 - Bouguer Map (Souza 1995) 
cisão de leitura e conseqüentemente maior precisão nos resultados finais.

Os dados gravimétricos obtidos em campo foram reduzidos das correções de deriva, latitude, ar-livre e Bouguer, para finalmente obter a anomalia Bouguer, para cada uma das estações, e, assim, elaborar-se o mapa Bouguer da área (Fig. 2).

Para todos os cálculos efetuados, adotou-se o valor de 2,67 gcm-3 para a densidade média da crosta, em concordância aos cálculos efetuados na elaboração da Carta Gravimétrica do Estado de São Paulo (IPT1985,1987). Tal procedimento teve por finalidade compatibilizar os dados gerados a partir deste levantamento com aqueles gerados nas áreas contíguas no processo de elaboração da referida carta, possibilitando desta forma uma futura análise global dos dados.

Posteriormente, estes dados de anomalia Bouguer foram ainda reduzidos da correcão de relevo, utilizando-se dos procedimentos apresentados em Surita (1990).

Os dados altimétricos necessários à efetivação destas correções foram extraídos de plantas na escala l: 10.000 (IGC 1989) em malhas com nós distanciados de $500 \mathrm{~m}$ (matrizes de 32 por 32 elementos) e complementados por dados extraídos de plantas topográficas na escala 1:50.000 (IBGE, 1974) em malhas de 1.000 por $1.000 \mathrm{~m}$. A frequência de amostragem dos dados topográficos levou em conta as sugestões abordadas em Surita (1990). Analogamente aos cálculos desenvolvidos para a obtenção da anomalia Bouguer, a densidade média adotada para os cálculos da correcão de relevo foi de 2,67 gcm-3.

Para o desenvolvimento dos cálculos de correcão de relevo, a área de estudo foi subdividida em cinco blocos: Cananéia, Cardoso, Paratiú, Barra e Iguape (Fig. 3). Em dois destes blocos (Paratiú e Barra), os dados altimétricos extraídos das plantas na escala 1: 10.000 , foram complementados por dados de plantas topográficas na escala 1:50.000, do IBGE, tendo em vista a inexistência de dados na escala desejada (l: 10.000) nestas áreas. Nestes casos, as amostragens ocorreram a cada quilómetro.

Os cálculos das correções de relevo dos cinco modelos topográficos extraídos da área de estudo foram executados através do programa CORR, escrito em linguagem Fortran77, apresentado em Surita (1990).

A análise dos dados obtidos permite concluir que a correcão de relevo sobre os dados gravimétricos obtidos na área investigada não é relevante e, portanto, não representa fator determinante na conformação final do mapa Bouguer, com exceção apenas das porções extremas da área investigada, ou seja, as ilhas de Iguape e do Cardoso, onde algumas estações

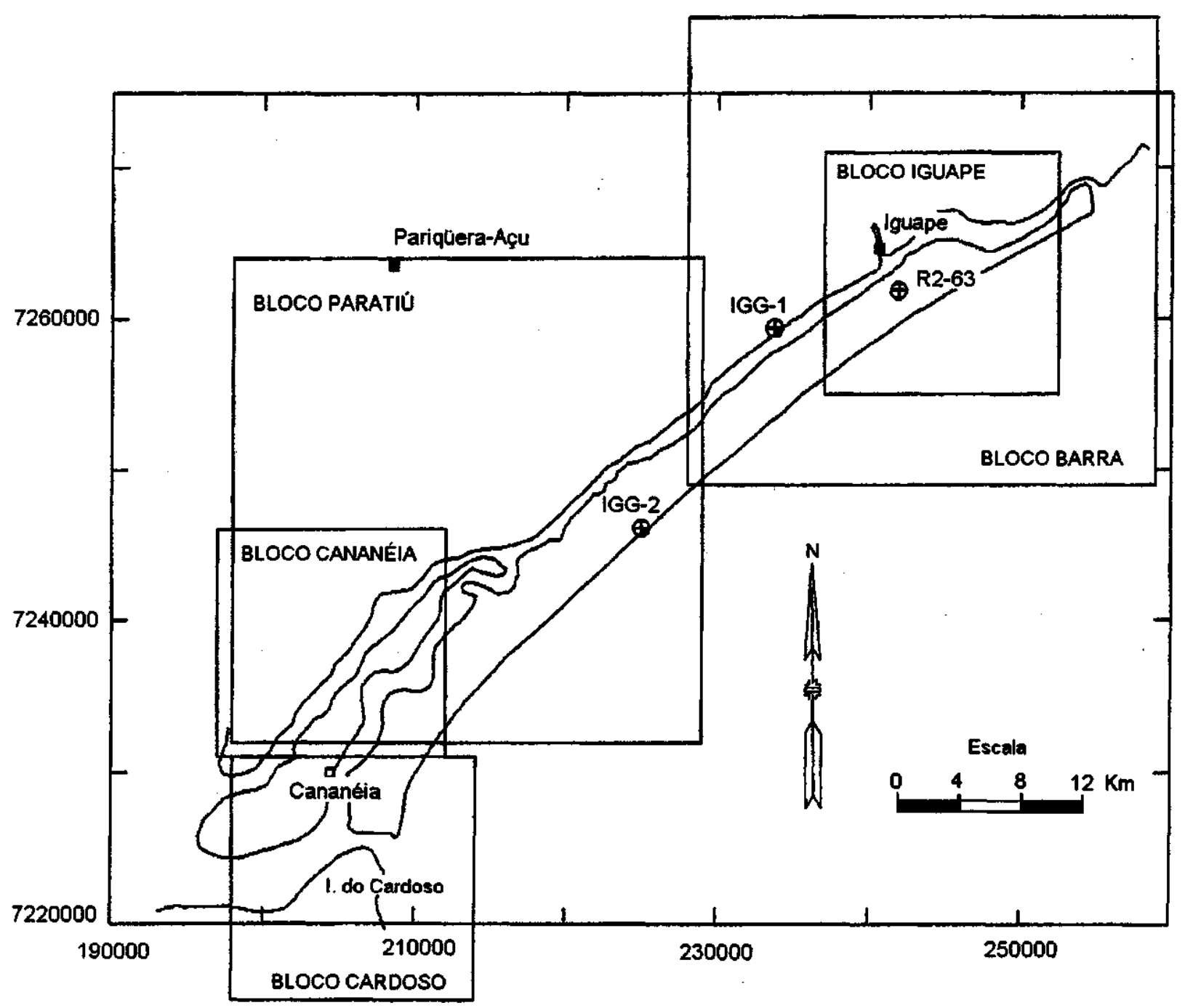

Figura 3 - Mapa de localização dos blocos topográficos utilizados para a aplicação da correcão de relevo Figure 3 - Location of topographic blocks for terrain correction 

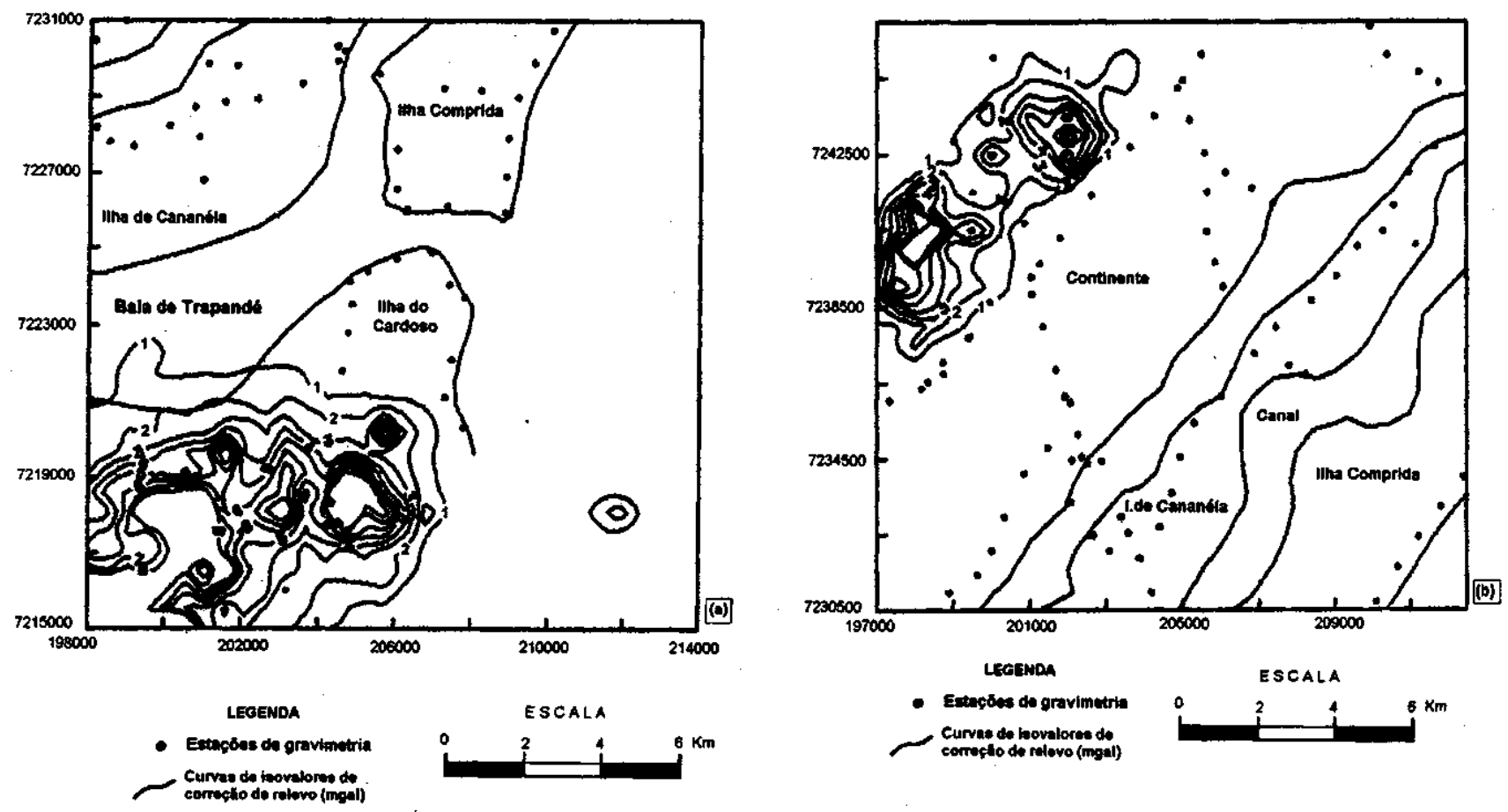

Figura 4 - Exemplo dos resultados obtidos com a aplicação da correção de relevo nos Blocos Cardoso (a) e Paratiu (b). Observa-se nestes mapas que a maioria das estações se localizam nos setores com correção de relevo menor que 1 mgal (Souza 1995). Figure 4 - Part of the results from terrain correction applied on gravity data: (a) Cardoso block; (b) Paratiu block. Note that many of the stations are located within the area with terrain correction lesser than $1 \mathrm{mgal}$ (SOUZA 1995)

gravimétricas foram instaladas em pontos bastante próximos dos maciços cristalinos que representam os setores com anomalias topográficas na área de estudo. Parte dos resultados obtidos da análise para correção de relevo pode ser observada na Figura 4.

\section{Interpretação dos Resultados Mapa Bouguer e Mapa de Anomalias Aeromagnétlcas As} anomalias gravimétricas observadas na área estudada foram analisadas sob dois pontos de vista principais. Em primeiro lugar, uma análise global do mapa Bouguer, pelo qual se observaram as formas, os gradientes e as orientações preferenciais das curvas de isovalores, correlacionando-se estas características com prováveis feições do substrato geológico da área; em segundo lugar, uma análise de dois perfis (PF1 e PF2), posicionados estrategicamente no mapa Bouguer, que fornece como produto um modelo para a topografia do embasamento cristalino ao longo da ilha Comprida.

A análise do mapa Bouguer da área em estudo deve levar em consideração algumas restrições, particularmente quanto à distribuição das estações gravimétricas, relativamente restritas às áreas correspondentes às ilhas Comprida e de Cananéia e área continental adjacente, privilegiando a análise dos dados, na forma de perfis longitudinais. Todavia, mesmo considerando-se tais restrições, destacam-se pelo menos três aspectos.

O primeiro refere-se ao alto gravimétrico com fortes gradientes laterais (anomalias de $-2 \mathrm{mgal}$ ), com localização que coincide aproximadamente com o poço IGG-1, apresentando um eixo principal na direção NW-SE. Este alto gravimétrico, denominado neste estudo de alto gravimétrico de Cananéia, é interpretado como efeito do embasamento cristalino, que neste setor da área investigada se projeta mais próximo da superficie (47 $\mathrm{m}$ de profundidade), conforme descrito no poço IGG-1. Este alto gravimétrico pode estar ainda representando uma zona de afinamento crustal, com o consequente soerguimento do embasamento e preenchimento, ou não, por diques, das fissuras geradas. Desta forma, este alto poderia ser correlacionado à continuidade do alinhamento Guapiara (Ferreira 1982a,b) sob a região da planície costeira CananéiaIguape. A posição relativa entres diques correspondentes ao alinhamento Guapiara e o alto gravimétrico detectado permite supor que este alinhamento se projeta sob a ilha Comprida (Fig. 5). Esta assertiva é corroborada pelo modelo do contorno da topografia do embasamento cristalino desta ilha, apresentado neste estudo. É corroborada ainda pelos dados aeromagnéticos (IPT 1994), já que conforme pode ser observado no mapa aeromagnético da área (Fig. 6), ocorre uma nítida tendência de alinhamento na direção NWSE das curvas de isovalores de anomalias aeromagnéticas. Este alinhamento pode ser correlacionado a alinhamentos estruturais do embasamento na direção NW-SE. A posição relativa entre o alinhamento Guapiara e o alinhamento aeromagnético observado, permite mais uma vez supor a continuidade do alinhamento Guapiara sob a planície costeira Cananéia-Iguape, no rumo da plataforma continental (Fig. 6).

$\mathrm{O}$ segundo refere-se ao baixo gravimétrico, localizado na porção SW da área investigada, denominado aqui de baixo gravimétrico de Cananéia, que pode, em princípio, ser correlacionado a uma maior espessura da cobertura sedimentar nesta área. De fato, a descrição do poço IGG-2, que atinge a profundidade de $167 \mathrm{~m}$, sem alcançar o embasamento, sugere que este se aprofunda, a partir do poço IGG-1, no sentido S W. Esta assertiva também se fundamenta no fato de que anomalias negativas, particularmente quando cercadas por 


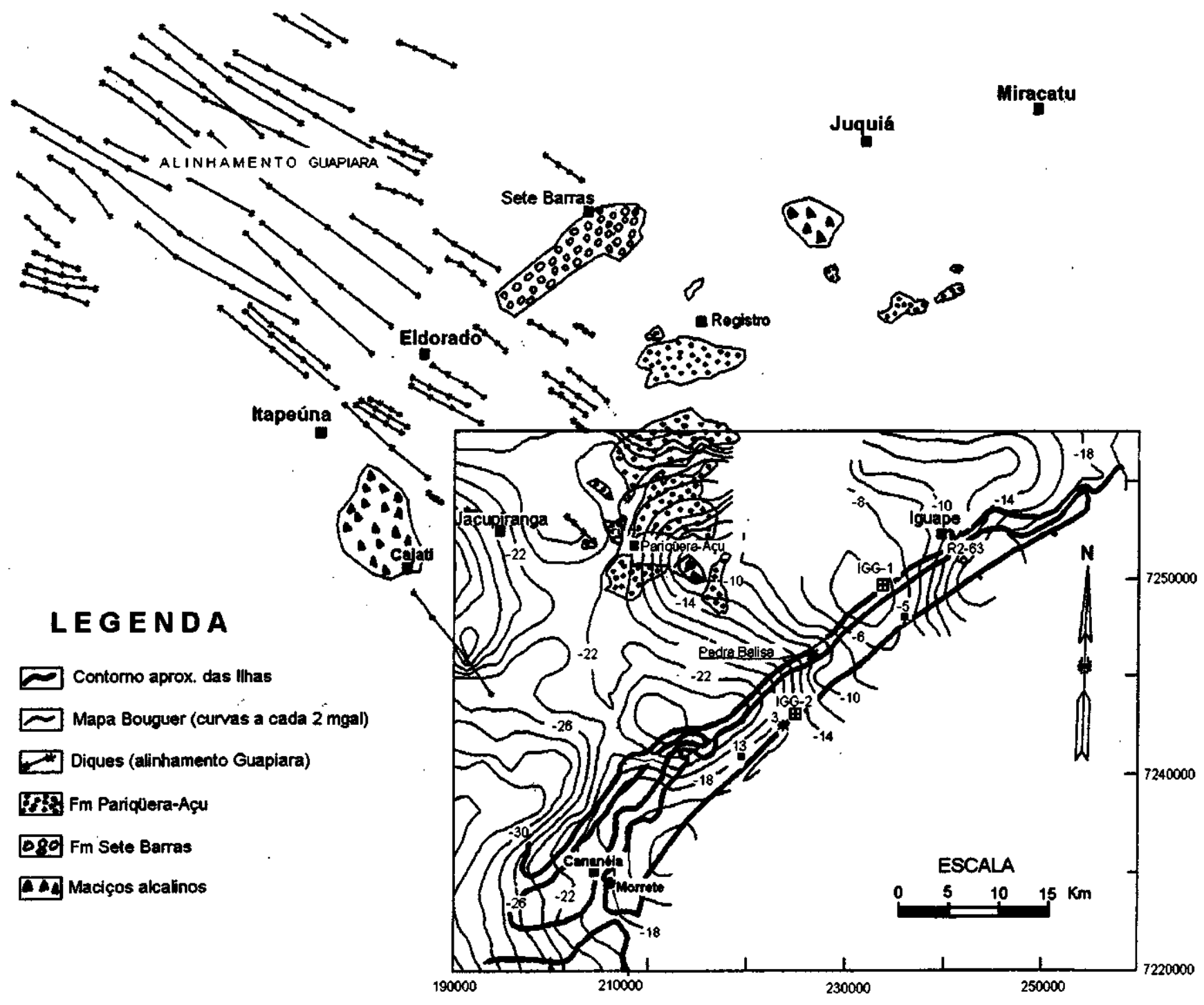

Figura 5 - O Alinhamento Guapiara e o mapa Bouguer (Souza 1995)

Figure 5 - Guapiara Alignment and Bouger map (Souza 1995)

fortes gradientes, como é o caso em foco, estão normalmente relacionadas com espessos pacotes de sedimentos, embora possam também, eventualmente, estar refletindo forte contribuição de corpos graníticos de baixa densidade (Ussami \& Bott 1989).

O terceiro, e último aspecto a ser realçado no mapa Bouguer, refere-se ao baixo gravimétrico localizado próximo à cidade de Iguape, a $N E$, denominado neste estudo de baixo gravimétrico de Iguape (Fig. 5). Analogamente à interpretação dada ao baixo gravimétrico de Cananéia, deve também traduzir a presença de uma espessa camada de sedimentos. De fato, ensaios geoelétricos executados na área (Daee 1979) indicaram espessura dos estratos sedimentares ao redor de 118 $\mathrm{m}$, valor este que parece estar subestimado.

As anomalias aeromagnéticas não refletem necessariamente a presença de diques (aflorantes ou não), podendo, entretanto, refletir anomalias decorrentes de um grupo de diques ou de um único dique com forte magnetização. Contudo, lineamentos observados em mapas aeromagnéticos podem traduzir feições estruturais no embasamento cristalino, preenchidas ou não por diques (Ussami et al. 1991).

A presença ou não de diques preenchendo estas estruturas, bem como sua orientação, poderia ser confirmada, a partir do refinamento dos estudos de mapeamento destes corpos, através da integração entre dados geológicos e dados de ensaios de magnetometria terrestre de detalhe, com espaçamento entre estações da ordem de 10-30 m.

Modelamento gravimétrico Para melhor analisar as principais anomalias observadas no mapa Bouguer e também de estimar a contribuição das fontes próximo à superficie (cobertura sedimentar, embasamento e granitos de baixa densidade aflorantes nas áreas adjacentes), sobre campo de anomalias gravimétricas observadas, foram estudados dois perfis ( $\mathrm{PF} 1$ e PF2) longitudinais à área de estudo (Fig. 7). $\mathrm{O}$ posicionamento destes perfis foi definido em virtude de que cortam perpendicularmente as anomalias destacadas no mapa Bouguer, ou seja, o alto gravimétrico de Cananéia e os baixos gravimétricos de Cananéia e Iguape. A localização destes perfis levou em conta também a importância de que eles 


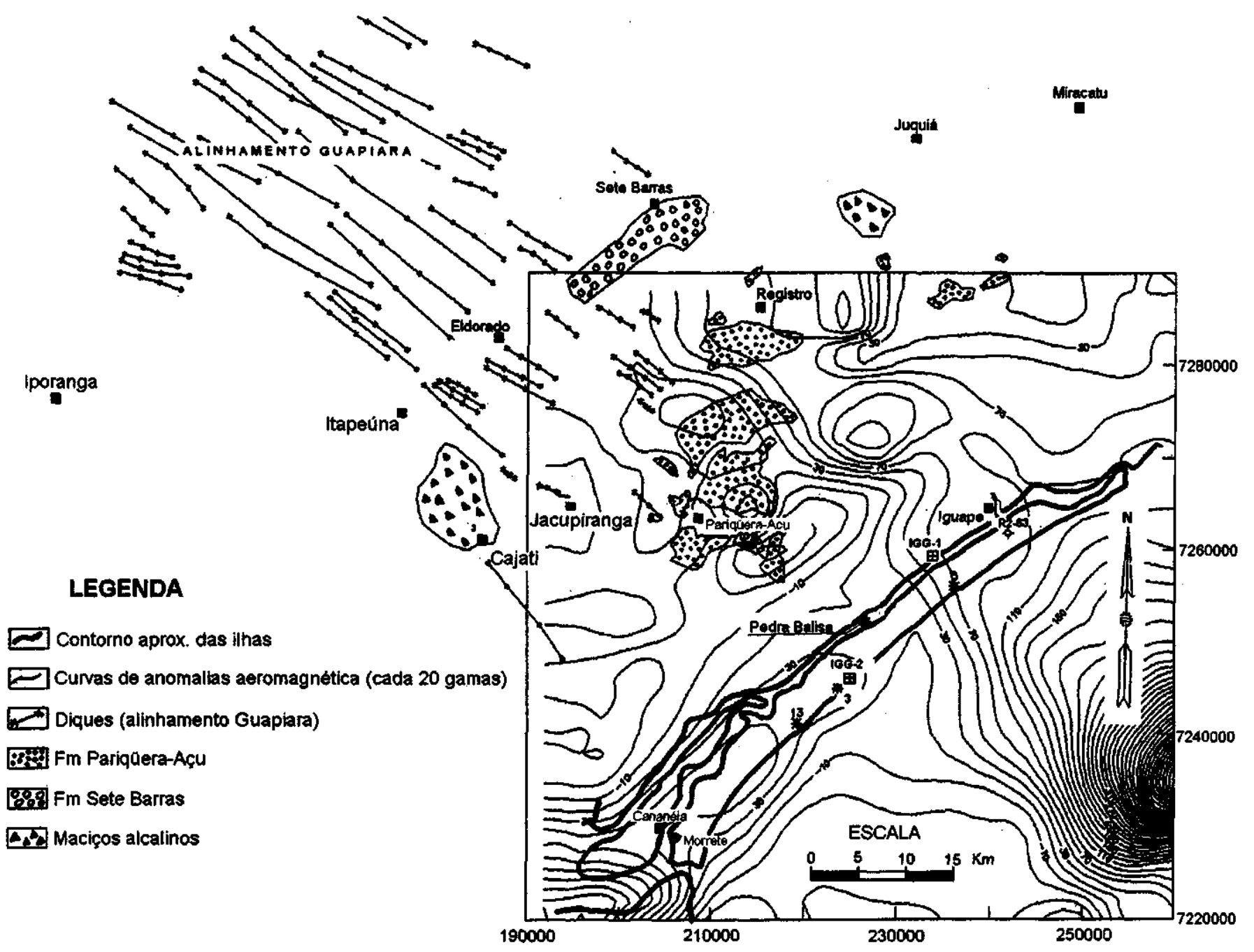

Figura 6 - O Alinhamento Guapiara e o mapa Aeromagnético (Souza 1995)

Figure 6 - Guapiara Alignment and Aeromagnetic Map (Souza 1995)

cruzassem pelos poços (IGG-1 e IGG-2), únicas informações diretas de subsuperficie existentes na área, e pelos pontos com informações geofísicas referidas em Petri \& Suguio (1971, 1973), Suguio \& Petri (1973) e Daee (1979). A geometria da área estudada (alongada na direção NE-SW), e a própria distribuição das estações levantadas (preferencialmente ao longo das ilhas Comprida e de Cananéia e área continental adjacente), também foi considerada na definição do posicionamento destes perfis.

A região em estudo está circundada por áreas de rochas Pré-cambrianas, que, apesar de ocorrerem a distâncias relativamente grandes $(5-10 \mathrm{~km})$ da maioria das estações gravimétricas implantadas, podem, no caso de possuir densidades anormalmente baixas (granitos de baixa densidade), influenciar as medidas realizadas, ampliando o valor da anomalia negativa observada, em princípio interpretada como causada por uma espessa cobertura sedimentar.

A avaliação de possível influência desses corpos graníticos (inicialmente supostos de baixa densidade e ocorrendo a profundidades não superiores a 6-8 $\mathrm{km}$ ), sobre os valores de anomalia Bouguer calculados, foi realizada através do modelamento dos dados.
Nos cálculos referentes ao modelamento, os efeitos profundos (anomalia regional) foram estimados e removidos das anomalias medidas com a finalidade de efetuar o modelamento e a interpretação das anomalias de pequeno comprimento de onda e provável fonte rasa. A remoção automática da anomalia regional, através dos processos computacionais, indicou valores ao redor de $14 \mathrm{mgal}$, corroborando os dados apresentados por Ussami \& Molina (1993).

Análise dos perfis gravimétricos A eventual existência de corpos graníticos de baixa densidade, circundando a área de estudo, pode influir no sentido de ampliar os valores das anomalias negativas observadas, o que pode levar o intérprete a erros na estimativa da espessura da cobertura sedimentar. Para avaliar a influência deste fator sobre as anomalias Bouguer calculadas, procedeu-se à simulação do efeito gravitacional destes supostos corpos sobre os dados obtidos, pressupondo-se que contrastes de densidade de até $0,15 \mathrm{gcm}-3$ e profundidades destes corpos de até $6-7 \mathrm{~km}$. Os corpos foram individualizados com base no mapa geológico da área, conforme pode ser observado na figura 7 . 


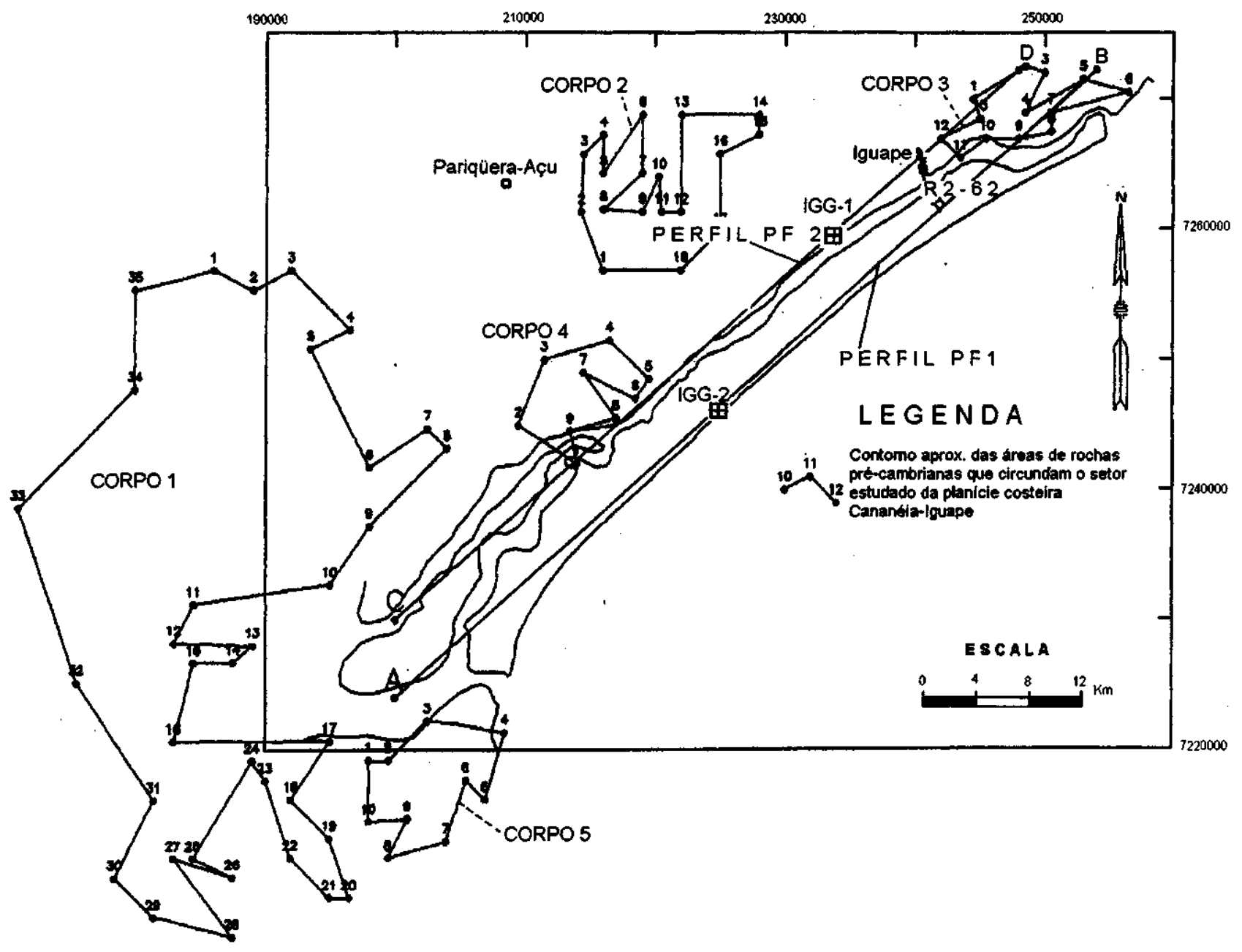

Figura 7 - Mapa do contorno aproximado dos corpos de rochas Pré-cambríanas na área estudada, utilizado nos cálculos de simulação do efeito gravimétrico de granitos de baixa densidade. Localização dos perfis PF1 e PF2 utilizados no modelamento dos dados gravimétricos

Figure 7 - Location of Pre-cambrian rocks around the studied area. Location of PFl and PF2 modeled profiles

As densidades das rochas utilizadas no modelamento foram definidas a partir de dados da literatura, já que não se procedeu, neste estudo, a qualquer ensaio para sua determinação.

Para o desenvolvimento do modelamento, estimou-se para a cobertura sedimentar (sedimentos marinhos e continentais) uma densidade média ao redor de $2,0 \mathrm{gcm}-3$, com possibilidades de variações entre 1,8 e 2,2 gcm-3.

$\mathrm{O}$ modelo inicial da topografia do embasamento cristalino ao longo destes perfis (PFl e PF2) foi estabelecido com base nos dados geológicos e geofísicos preexistentes, principalmente com base nos dados dos poços IGG-1 e IGG-2.

O processo de ajustamento do modelo proposto para a topografia do embasamento ao longo dos dois perfis, aos dados geofísicos obtidos (g observado), foi realizado com o auxílio do programa Open File Report 92-18 - US Geological Survey Potential-Field Geophysical Software.

$\mathrm{O}$ produto final do modelamento dos perfis PF1 e PF2, considerando-se a simulação de influências ou contribuições dos supostos corpos graníticos de baixa densidade, está representado na figura 8 .

A partir da análise efetuada, pode-se concluir que a eventual existência de corpos graníticos de baixa densidade circun- dando a área de estudo contribuiria de forma expressiva nos valores das anomalias gravimétricas observadas, somente em duas situações: quando o perfil ou a estação gravimétrica estivesse muito próxima do corpo granítico ou quando o perfil ou a estação gravimétrica se localizasse sobre o corpo granítico. Desta forma, conclui-se que, de acordo com dos objetivos deste estudo e devido à grande distância entre as estações e supostos corpos graníticos, os valores obtidos de contribuição destes corpos podem ser desprezados.

Finalmente, a proposta para a conformação do embasamento cristalino ao longo dos perfis PFl e PF2, estabelecida a partir do modelamento dos dados gravimétricos executados neste estudo, está representada através do blocodiagrama da figura 9.

Conclusões A análise dos dados gravimétricos associada aos dados geológicos e geofísicos preexistentes permite admitir um condicionamento tectônico para o arcabouço estrutural da planície costeira Cananéia-lguape, provavelmente relacionado com eventos cenozóicos responsáveis pela formação do rifte continental do Sudeste do Brasil (Souza 1995). 


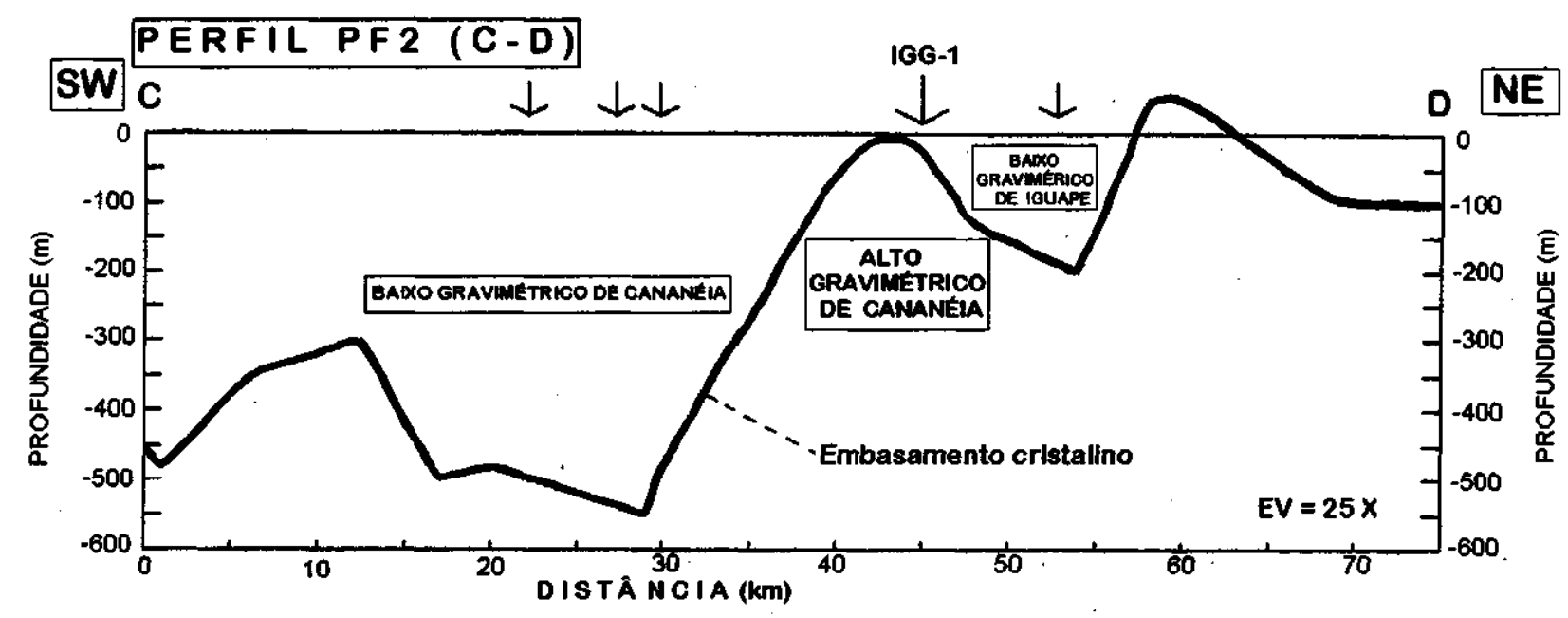

\section{PERFIL PF1 (A-B)}

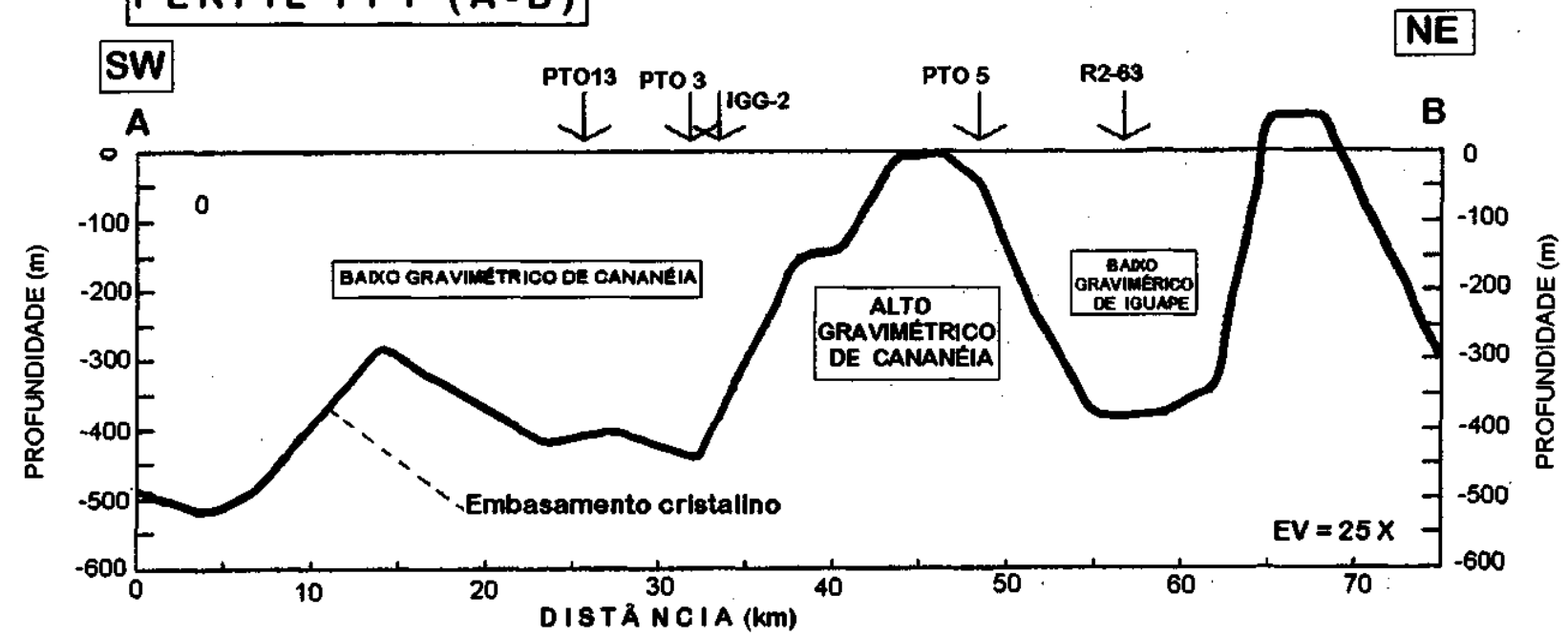

Figura 8 - Contorno do embasamento ao longo dos perfis PF1 e PF2, produto final do modelamento dos dados gravimétricos (Souza 1995)

Figure 8 - Profiles based on PFl and PF2 modeled profiles (Souza 1995)

A análise do mapa Bouguer final e do produto do modelamento dos perfis gravimétricos PFl e PF2 indica a presença de um alto gravimétrico(alto gravimétrico de Cananéia) na porção nordeste da área estudada, alinhado na direção NW-SE e com fortes gradientes laterais nos rumos SW e NE, que sugerem a presença de falhas, provavelmente normais, delimitando o bloco emergente. Os mapas de anomalias gravimétricas, analisados conjuntamente com o mapa de anomalias aeromagnéticas, permitem admitir a existência de estruturação do embasamento na direção NW-SE, que sugere continuidade do alinhamento Guapiara no rumo SE, da plataforma continental externa (bacia de Santos). As feições identificadas a partir desta análise representariam zonas de fraqueza da crosta, definindo estruturas, possivelmente, preenchidas por diques de rochas vulcânicas.

A existência de um baixo gravimétrico (baixo gravimétrico de Cananéia) na área a S W do poço IGG-2 está relacionada com provável deficiência de massa neste setor, o que corresponderia à presença de espesso pacote de sedimentos. Ao norte, próximo à cidade de Iguape, outro baixo gravimétrico (baixo gravimétrico de Iguape) foi identificado, que, analogamente, pode ser correlacionado à presença de espessa coluna sedimentar.

$\mathrm{Na}$ análise de produtos de sensores remotos (imagem de satélite e fotografias aéreas) e também dos mapas de anomalia gravimétrica, observa-se a presença de lineamentos estruturais nas direções EW, NE-SW e NW- SE. Estas direções estão de acordo com as principais direcões estruturais na área, isto é, o alinhamento Guapiara (NW-SE) e as faixas de cisalhamento Pré-cambrianas (NE-SW). Estudos realizados por Melo (1990) revelam que as falhas normais que cortam o embasamento e delimitam o gráben Sete Barras seriam resultado de esforços de tração orientados nas direção E-W a WNW-ESE, concordante, inclusive, com a direção dos esforços de tração definidos para as bacias de São Paulo, Taubaté, Resende e Volta Redonda (Riccomini 1989). Assim, a análise dos dados obtidos permite supor que o condicionamento estrutural deste setor da costa paulista está diretamente relacionado com a reativação, durante o Cenozóico, das estruturas preexistentes (alinhamento Guapiara e as faixas de cisalhamento Pré-cambrianas). O mesmo raciocínio desen- 


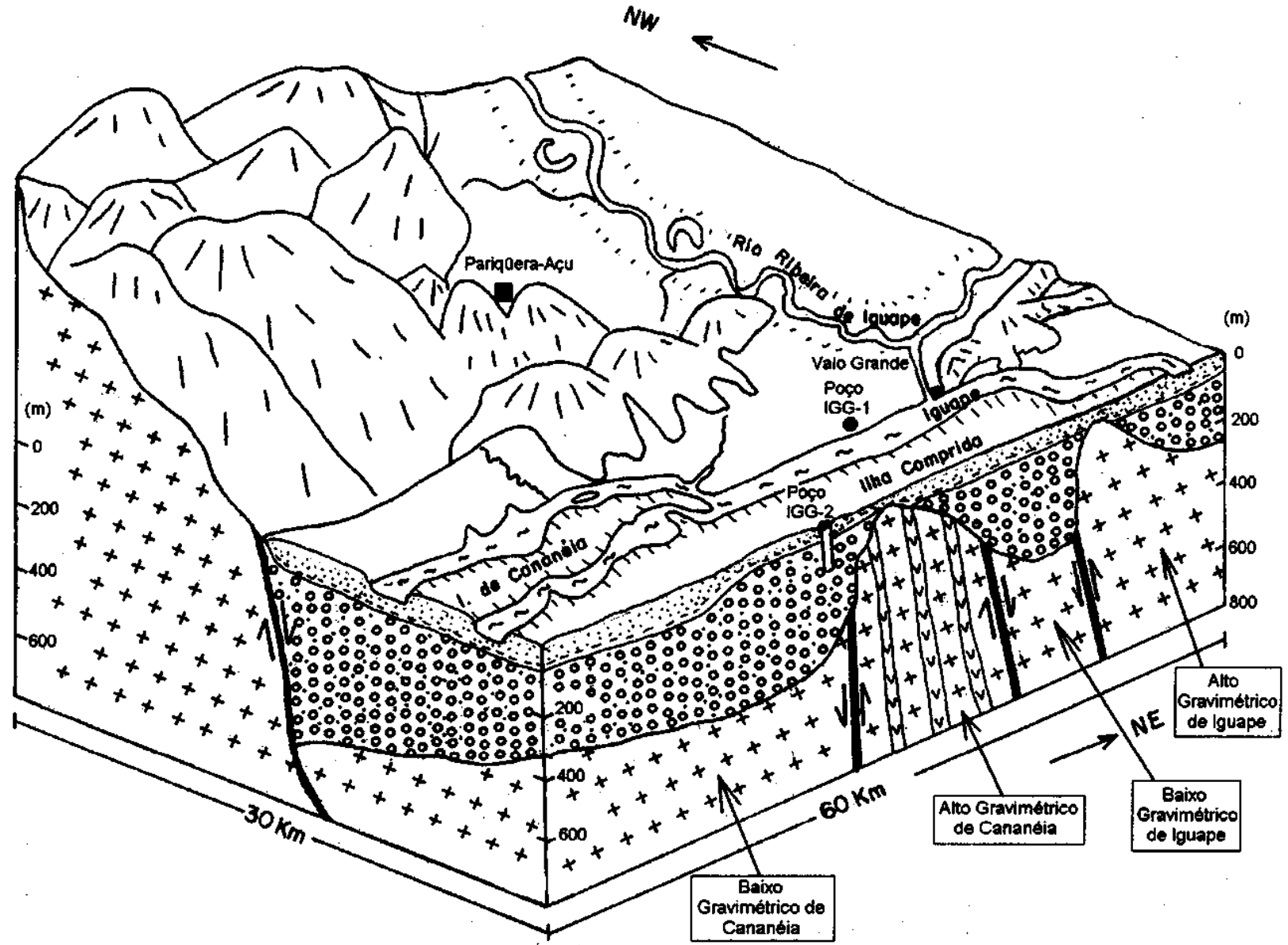

\section{LEGENDA}

$\sqrt{ }$ Azona de falmas

PLANICIE COSTEIRA CAMANÉla-guAaPE

SEDIMENTOS ARENOSOS NO TOPO,ARGILO-

i: SILTOSOS CI FORAMINIFEROS NA PORGĀO

INTERMEDIARIA E SHTTE-ARGILOSOS CI

DIATOMÁCEAS NA BASE (SEQüÊNCIAS II, III

EIV DE PETRI \& SUGUIO, 1971)

OO CONGLOMERADOS E ARENITOS CONGLO

D- MERÁTICOS COM NIVEIS ARGILOSOS

b'0 (SEQUENMCIA I DE PETRI \& SUGUIO,1971)

ESTRUTURAS DO EMBASAMENTO MA

DIRECAOO NW, RELACIONADAS AO ALINHA-

MENTO OUAPIARA, PROVAVELMENTE

PREENCHIDAS POR DIQUES DE DIABÁSIO

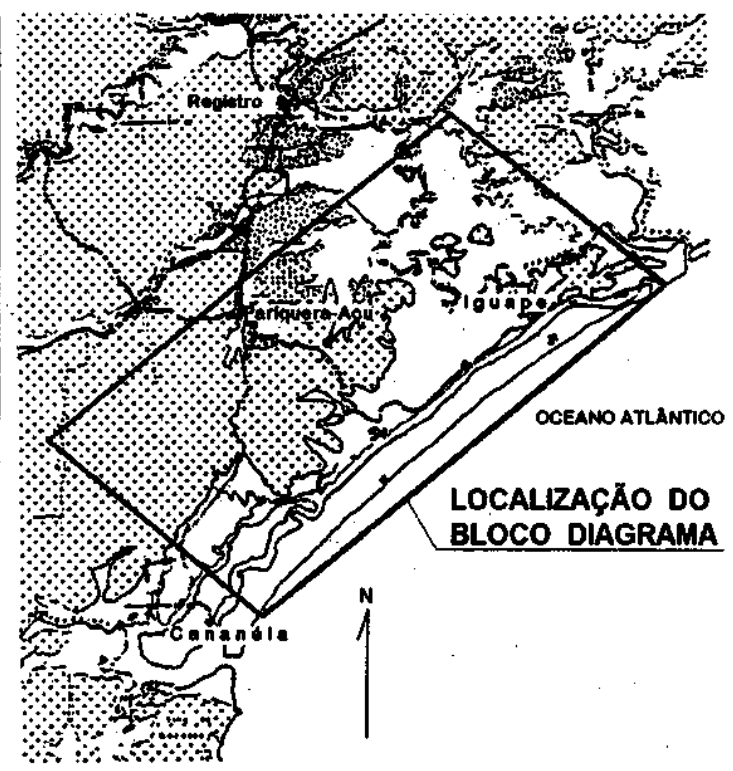

EMBasamento cristalino

Figura 9 - Bloco-diagrama com as principais feições estruturais identificadas na planície costeira Cananéia-lguape (Souza 1995) Figure 9 - Diagram showing the main structural features in the Cananéia-lguape coastal plain (Souza 1995) 
volvido por Melo (1990), sobre a evolução do gráben Sete Barras, poderia ser aplicado ao setor estudado, particularmente com relação à área do baixo gravimétrico de Cananéia, considerando-se que estes setores, além de relativamente próximos, possuem outras semelhanças como: direções estruturais, formas alongadas na direção NE-SW, provável basculamento de blocos e espessa camada de sedimentos grossos.

A análise sismológica da área (Mioto 1984) indica a ocorrência recente de dois sismos de alta intensidade com epicentro exatamente na área correspondente ao baixo gravimétrico, na ilha de Cananéia. Indica também a ocorrência de outro sismo ainda de maior intensidade, com epicentro na plataforma interna, a cerca de $30 \mathrm{~km}$ da costa. A ocorrência destes sismos levou à definição da Zona Sismogênica de Cananéia (IPT 1984). Este fato corrobora os dados obtidos neste estudo permitindo admitir movimentos tectônicos recentes para este setor da planície costeira Cananéia-Iguape, mesmo porque zonas simogênicas denotam mobilidade crustal que muitas vezes pode ser diretamente correlacionada à história cenozóica de um determinado local (Mioto 1993).

No modelamento gravimétrico, a análise dos perfis PF1 e PF2 indica espessamento da cobertura sedimentar a partir da faixa costeira no sentido do continente, na área do baixo gravimétrico de Cananéia. Por outro lado, na área do baixo gravimétrico de Iguape, os perfis modelados revelam aumento da espessura do pacote de sedimentos no sentido da plataforma interna, o que permite supor a existência de condições estruturais distintas para estas duas porções da área investigada. Para a área do baixo gravimétrico de Cananéia, condições estruturais favoráveis (falhas normais) teriam propiciado um basculamento de blocos para NW, o que poderia ser explicado pela existência de um gráben ou um semigráben, originado dos mesmos processos tectônicos cenozóicos responsáveis pela formação de feições análogas de outras regiões do País (por exemplo, gráben de São João, localizado na região entre Búzios e Macaé, no Estado do Rio de Janeiro, e gráben Sete Barras, no sudeste do Estado de São Paulo). Assim, a formação deste suposto gráben teria estreita relação com a formação do rifte continental do Sudeste do Brasil e bacias correlatas.

Para o caso do baixo gravimétrico de Iguape, um condicionamento tectônico teria proporcionado basculamento para SE, já que no modelamento dos perfis PF1 e PF2 se observa aumento da espessura do pacote de sedimentos, no sentido da plataforma continental. Lineamentos estruturais de direção geral E-W ou NE-SW, coincidência entre xistosidade e direção destes lineamentos, resultados de análises petrográficas das rochas das encostas cristalinas mostrando cataclasamento do seus minerais, entre outros, são alguns dos argumentos que levaram Pressinotti \& Pressinotti (1980) a supor, também, que a gênese da planície costeira Cananéia-Iguape fosse tectônica, gerada a partir de falhamentos de gravidade e abatimento de blocos costeiros.

Os dados do poço IGG-2 indicam espessura mínima de 118 $\mathrm{m}$ para os sedimentos grossos (conglomerados e areias conglomeráticas). O modelamento dos dados gravimétricos obtidos indica a existência de uma coluna sedimentar com espessura superior a $400 \mathrm{~m}$, na área a SW desta sondagem, o que por sua vez pode significar que a espessura de sedimentos grossos pode ser, em alguns trechos, bastante superior aos 118 $\mathrm{m}$ identificados no poço IGG-2. Processos de erosão e sedimentação continentais convencionais não explicariam por si só a construção de uma coluna sedimentar deste porte. A presença de fenômenos tectônicos relacionados com a reativação de falhas antigas, associada ou não a processos epirogenéticos, constitui-se necessariamente em argumentos na busca de explicações para esta ocorrência.

\section{REFERÊNCIAS}

ALMEIDA, F.F.M. 1976. The system of continental rifts bordering the Santos basin. Intern. In: Symposium on Continental Margins of Atlantic Type. Anais da Academia Brasileira de Ciências, v.48 (suplemento), p. 15-26.

D ABE - DEPARTAMENTO DE ÁGUAS E ENERGIA ELÉTRICA. 1979. Estudo de águas subterrâneas - região administrativa 2 - Santos. Governo do Estado de São Paulo, Secretaria de Obras e Meio Ambiente, Departamento de Águas e Energia Elétrica. Relatório interno, v.1 - texto, v. 2 - mapas, v. 3 - anexos.

FERREIRA, F.J.F. 1982a. Interpretação de dados aeromagnéticos e geológicos: configuração e evolução tectônica do Arco de Ponta Grossa. Dissertação de Mestrado, Instituto de Geociências da USP, SP. 169p.

FERREIRA, F.J.F. 1982b. Alinhamentos estruturais - magnéticos da região centro - oriental da bacia do Paraná e seu significado tectônico. In: Geologia da bacia do Paraná. São Paulo, IPT. p. 143-166. (Publicação especial $\left.n^{\circ} 12\right)$

FERREIRA, F.J.F.; MORAES, R.A.V.; FERRARI, M.P. \& VIANNA, R.B. 1981. Contribuição ao estudo do alinhamento estrutural de Guapiara. In: Simpósio Regional de Geologia, 3, Curitiba, SBG-Núcleo de São Paulo. Atas..., v.l, p.226-240.

FÚlfarO, V.J.; SUGUIO, K. \& PONÇANO, W.L. 1974. A gênese das planícies costeiras paulistas. In: Congresso Brasileiro de Geologia, 28, Porto Alegre. Anais... SBG, v.3,p.37-42.

GEOBRÁS S/A. 1966. Complexo Valo Grande, Mar Pequeno e Rio Ribeira de Iguape. Relatório da Geobrás S/A -Engenharia e Fundações para o Serviço do Vale de Ribeira do Departamento de Águas e Energia Elétrica do Estado de São Paulo. 2v.

IBGE - INSTITUTO BRASILEIRO DE GEOGRAFIA E ESTATÍSTICA. 1974. Carta do Brasil - Escala 1:50000. Folhas: Cananéia, Ilha de Cananéia, Barra do Ribeira, Subauma, Rio Guaraú, Pariqüera-Açu, Iguape, Ariri. Superintendência de Cartografia - Departamento de Cartografia.
IGC - INSTITUTO GEOGRÁFICO E CARTOGRÁFICO. 1989. Plantas Topográficas na escala 1: 10.000. Plano cartográfico do Estado de São Paulo. Governo do Estado de São Paulo -Secretaria de Economia e Planejamento.

INSTITUTO DE PESQUISAS TECNOLÓGICAS DO ESTADO DE SÃO PAULO - IPT - 1984. Análise de risco sísmico do Estado de São Paulo. Estabelecimento de medidas de proteção comunitária. (Relatório IPT, 20.573).

1985. Carta Gravimétrica do Estado de São Paulo. (Relatório IPT, 22.546, Fase A).

1987. Carta Gravimétrica do Estado de São Paulo. (Relatório IPT, 25.645, Fase B)

1989. Compartimentarão estrutural e evolução tectônica do Estado de São Paulo.(Relatório IPT, 27.394).

1994. Base de dados magnetométricos do Brasil. Mapa do campo magnético anômalo do Brasil e da área oceânica adjacente. (Relatório, IPT 31.952).

MARTIN, L.; BITTENCOURT, A.C.S.P.; FLEXOR, J.M. \& VILAS BOAS, G.S. 1984. Evidências de um tectonismo quaternário nas costas do Estado da Bahia. In: Congresso Brasileiro de Geologia, 33, Rio de Janeiro. Anais... SBG, v.l, p.19-27.

MARTIN, L. \& SUGUIO, K. 1975. The state of São Paulo costal Marine Geology - "The ancient strand lines". Anais da Acad. Brasileira de Ciências. Curitiba, v.47 (supl.), p.249-263.

MELO, M.S. 1990. A formação Pariqüera-Acu e depósitos relacionados: sedimentação, tectônica e geomorfogênese. Dissertação de Mestrado, Instituto de Geociências da USP, 21 Ip.

MIOTO, J.A. 1983. Mapa de risco sísmico do sudeste brasileiro. Dissertação de Mestrado, Escola de Engenharia de São Carlos, USP.

MIOTO, J.A. 1984. Mapa de risco sísmico do sudeste brasileiro. São Paulo (IPT, Publicação 1563 - Série Monografias, 10).

MIOTO, J.A. 1993. Sismicidade e zonas simogênicas do Brasil. Tese de Doutoramento, Instituto de Geociências e Ciências Exatas, UNESP, SP. 2 vols. 558 p. 
MIRANDA, L.O.S. 1970. Geologia das bacias na plataforma sul brasileira. In: Congresso Brasileiro de Geologia, 24, Brasília, DF. Anais...v.l, p.129-140.

PETRI, S. \& FÚLFARO, V.J. 1970. Nota sobre a geologia e terraços marinhos da Ilha do Cardoso, SP. Not. Geomorfológicas, Campinas, 10 (20), p.21 -31.

PETRI, S. \& SUGUIO, K. 1971. Some aspects of the Neocenozoic sedimentation in the Cananéia-Iguape Lagoonal regioon, São Paulo, Brasil. Estudos Sedimentológicos, Universidade Federal do Rio Grande do Norte, 1(1): p.25-33.

PETRI, S. \& SUGUIO, K. 1973. Stratigraphy of the Iguape-Cananéia lagoonal region sedimentary deposits. São Paulo, Brasil. Part II: Heavy minerais studies, microorganisms inventories and stratigraphical interpretations. Bol. IG. (Instituto de Geociências da USP) V.4, p.71-85, São Paulo.

PRESSINOTTI, P.C. \& PRESSINOTTI, M.M.M. 1980. Contribuição à geologia dos arredores de Registro, SP. Rev. IG, 1(2), p.5-24.

RICCOMINI, C. 1989. O rift continental do sudeste do Brasil. Tese de Doutoramento, Instituto de Geociências, USP, 256p.

RICCOMINI, C; TESSLER, M.G. \& SUGUIO, K. 1987. Novas evidências de atividade tectônica moderna no sudeste brasileiro: os depósitos falhados da Formação Pariquera-açu. Proceedings of GCP Project 201, Merida (Venezuela) Meeting, ABEQUA, Publicação especial $n^{\circ}, p .29-42$

SOUZA, L.A.P -1995. A planície costeira Cananéia-Iguape, litoral sul do Estado de São Paulo: um exemplo de utilização de métodos geofísicos no estudo de áreas costeiras. Dissertacão de mestrado apresentada ao Instituto Oceanográfico da USP. 207p.lv.

SUGUIO, K. \& MARTIN, L. 1978a. Formações quaternárias marinhas do litoral paulista e sul fluminense. In: International Symposium on Costal Evolution in the Quaternary - Special Publicaton $n^{\circ} 01$ - The Brazilian National Working Group for the IGCP; Project 61, Instituto de Geociências da USP

SUGUIO, K. \& MARTIN, L. 1978b. Mapa geológico do litoral paulista, Folhas Cananéia e Iguape, escala 1:100.000, São Paulo, DAEE.
SUGUIO, K. \& PETRI, S. 1973. Stratigraphy of the Iguape-Cananéia lagoonal region sedimentary of the Iguape- Cananéia lagoonal region sedimentary deposits, São Paulo, Brasil. Part I: Field observations and grain size analysis. Boi. I.G., Instituto de Geociências da USP, vol 4, p. 1-20, São Paulo.

SURITA, C. A. 1990. Aplicacão da transformada de Fourier na correcão de relevo. Dissertação de Mestrado, Instituto Astronômico e Geofísico da Universidade de São Paulo, 145p.

TEISSEDRE JM. LOPES, M.F.C. SANCHES, J.L \& SILVA W.F. 1981. Contribuição da Hidrogeologia ao conhecimento estrutural do litoral paulista. In: Simpósio Regional de Geologia, 3, Curitiba. Atas..., SBG, v.l, p. 369-380.

TESSLER, M.G. 1982. Sedimentação atual na região lagunar de Cananéia-Iguape, Estado de São Paulo. Dissertação de Mestrado, Instituto de Geociências da Universidade de São Paulo, SP, 2 v. 169p.

TESSLER, M.G. 1988. Dinâmica sedimentar quaternária no litoral sul paulista. Tese de Doutoramento, Instituto de Geociências da USP, SP. 1 v. 276 p.

USSAMI, N. \& BOTT, M.H.P. 1989. A gravity study of the Paramirim granite, Bahia State of Brazil. Revista Brasileira de Geociências, v.2, $\mathrm{n}^{\circ} 19$, p. $170-176$.

USSAMI, N. KOLISNYK, A. RAPOSO, MIB; FERREIRA, F J.F; MOLINA, E.C. \& ERNESTO, M. 1991. Detectabilidade magnética de diques do arco de Ponta Grossa: um estudo integrado de manetometria terrestre/aérea e magnetismo de rocha. Revista Brasileira de Geociências, 21(4), p. 317-327.

USSAMI; SÁ, N.C. de \& MOLINA, E.C. 1993. Gravity map of Brazil, 2. Regional and residual anomalias and their correlation with major tectonic provinces. Journal of Geophysical Resources (Solid Earth), 98, n B2, p. 2199- 2208.

MANUSCRITO A901

Recebido em 16 de dezembro de 1996

Revisã o dos autores em 4 de abril de 1997 Revisã 0 aprovada em 6 de abril de 1997 